largely fulfilled. Assuming a certain acquaintance with basic statistical methods, a wide variety of problems peculiar to assay work is introduced, and the appropriate analytical procedures are explained, illustrated and discussed. Thus there are chapters dealing with parallel line assays; slope ratio assays; quantal responses; symmetrical designs ; efficiency, reliability and sensitivity ; incomplete block designs ; cross-over designs ; use of concomitant information; combination of estimates, etc., etc. There is also a fairly extensive bibliography and seventeen appendix tables giving the distributions of $t, \chi^{2}$, Fisher-Behrens ratio and variance ratio, as well as all the usual tables of transformations, working values, ranges, and weighting coefficients, for probits, logits, angles and loglogs. A great many general statistical techniques are introduced into the text and full explanations are given of their application and interpretation. As a result, the book is a more or less self-contained handbook on the subject, valuable as a work of reference both to the practitioner of bioassay and to the student of the primarily statistical aspects. One useful feature is the inclusion of four suggested alternative selections of sections from the book designed to meet the needs of the professional statistician desiring a short course in biological assay, the non-mathematical user of assay, the reader requiring a general survey of the function of statistics in the subject, and the reader who is mainly interested in work with quantal responses.

The general excellence of Statistical Method in Biological Assay justifies, in the opinion of the reviewer, the somewhat high price. Because of its comprehensive treatment and lucid exposition, Dr Finney's book deserves to be widely read and to become a standard work of reference in the field of bioassay.

Norman T. J. Bailey.

EVOLUTION IN THE GENUS DROSOPHILA. By J. T. Patterson and W. S. Stone. New York: The Macmillan Company. 1952. Pp. 1-599. $\$ 8.50$.

The evidence of evolutionary processes is at once more comprehensive and more significant in Drosophila than in any other group of animals or plants. It is derived from comparative anatomy, geographical distribution and ecology, combined with breeding and chromosome studies of many hundreds of species and of races in all parts of the world. This book is an account of the evidence accumulated, chiefly since rgIo, to which the authors and their collaborators have so largely contributed.

Each of the different aspects of Drosophila evolution is considered in some detail and particularly later in relation to the bases of genetic isolation. In general the authors keep their eyes fixed on one problem at a time and they do not allow themselves to be distracted, by what seem irrelevant clues, from their appointed programme. This is a successful policy up to a point. But, beyond that point, the desire to solve problems which were envisaged at the beginning suppresses the tendency for new problems to push their way into the discussion.

Moreover, we find that, in keeping with this attitude, the text has been put together in detail as though from an index of notes or reprints classified chiefly under the names of authors. Nearly half the paragraphs begin with these names (sometimes three or four of them): the connexion between such paragraphs will not be clear to the reader unacquainted with the hundreds of interesting personalities mentioned. On a larger scale the order of the book is confused in another way. For example there are 56 pages of sporadic references to salivary gland chromosomes before 
the authors take the plunge and tell us how the meaning of these chromosomes was discovered. Even so they do not tell us the part played in this by Heitz and Bauer who arrive on the scene a year late.

Such discontinuities of style and arrangement are not unrelated to the theoretical character of the book. "Natural Selection" appears (p. 264) as a sub-heading between, and on an equal footing with, "Gene Homologies" and "Genic Balance". "Genetic system" is equated with "genome" (p. 112) : whether the same equation holds later (on p. 537) is doubtful. But perhaps most serious of all is the authors' inevitable failure to take advantage of the specific opportunities of discovering fundamental principles from these very experiments with Drosophila.

Of the 121 diagrams which illustrate types of chromosome complement in the male, about 30 per cent. reveal no difference between $\mathrm{X}$ and $\mathrm{Y}$ chromosomes. In some instances as an afterthought the authors call attention to this apparent identity, e.g. " The largest $\mathrm{V}$ is the $\mathrm{X}$ chromosome ; and the $\mathrm{Y}$ is also a V, which is indistinguishable from the $\mathrm{X}$ " (p. 147). Now evolution in the sex chromosomes is clearly rapid in Drosophila : four species are represented as having no $\mathrm{Y}$ at all in the male; others have two X's. Certain questions therefore arise. Are the two apparently identical sex chromosomes a newly arisen system with a single gene difference? Or are there large but equal-sized differential segments in $\mathrm{X}$ and $\mathrm{Y}$ ? Or has the female become the heterozygous sex in these races or species?

To all these questions the salivary gland chromosomes and the distribution of heterochromatin might provide answers. But these matters are not brought into relation. Indeed, in the enormous index, sex chromosomes, or chromosomes : sex, or crossing-over, or linkage, or differential segments, do not appear.

This book, it is to be feared, will not be attractive to the general student : at least not so attractive as the importance of its theme suggests or deserves. Nevertheless it should fulfil a special purpose. For one who knows what he wants to find out from Drosophila, one who is already familiar with its genetical history and uses, and with the problems of evolutionary genetics in general, for such a one the references, tables, figures, diagrams and maps will suggest any number of new enquiries.

C. D. D.

GENETICS FOR SCHOOLS. By Prof. K. Mather, F.R.S. Modern Science Memoirs, No. 31. London : Published for the Science Masters' Association by John Murray. Pp. 36. 1s. 6d.

A valuable first year's course in all aspects of genetics : plant and animal, cytological and physiological, practical and theoretical.

THE BIOLOGY OF MENTAL HEALTH AND DISEASE. With 108 Contributors. Foreword by Stanley Cobb, M.D. London : Cassell. Pp. i-xvii+654. 75s.

This book contains $3^{8}$ articles, two of which, by F. J. Kallmann and R. R. Gates, and a discussion of mongolism, are of genetic interest.

\section{NEW JOURNALS}

JOURNAL DE GÉNÉTIQUE HUMAINE. No. 1 of Vol. 1 published June 1952. Genève : Médecine et Hygiène. (4 numbers per annum : Fr. fr. 3000 p.a.)

ACTA GENETICAE MEDICAE ET GEMELLOLOGIAE. No. 1 of Vol. 1 published January 1952. Rome: Largo Dell'Amba Aradam, 1. 65 p.a. 